\title{
AstraZeneca COVID-19 vaccine: A possible risk factor for Stroke, Case Series
}

Amira Siddig Omer ${ }^{1}$, Abbasher Hussien Mohamed Ahmed ${ }^{2}$, Khabab Mohamed Ahmed ${ }^{2}$, Abdallah M. Abdallah ${ }^{3}$, Mohamed Malekaldar ${ }^{4}$, AlHussien Abbasher ${ }^{5}$, Mohammed Abbasher ${ }^{1}$, and Abubaker Alsedig Abbasher ${ }^{6}$

${ }^{1}$ Al-Neelain University Faculty of Medicine

${ }^{2}$ University of Khartoum Faculty of Medicine

${ }^{3}$ University of Bahri, Faculty of medicine

${ }^{4}$ Omdurman Teaching Hospital

${ }^{5}$ AlYarmouk college

${ }^{6}$ Zamzam University college

December 22, 2021

\begin{abstract}
Cerebrovascular accident (CVA) is one of the commonest neurological deficits. There is a well-known association between COVID-19 and stroke. We present a case series of Sudanese patients who developed CVA after receiving the AstraZeneca COVID-19 vaccine suggesting a relationship between the vaccine and CVA.
\end{abstract}

\section{Hosted file}

Astrazeneca-h-1.docx available at https://authorea.com/users/448025/articles/550328-

astrazeneca-covid-19-vaccine-a-possible-risk-factor-for-stroke-case-series

\section{Hosted file}

AsraZeneca files.docx available at https://authorea.com/users/448025/articles/550328astrazeneca-covid-19-vaccine-a-possible-risk-factor-for-stroke-case-series 